\title{
Physician-Patient Relationship and Medication Compliance: A Primary Care Investigation
}

\author{
Ngaire Kerse, $\mathrm{PbD}, \mathrm{MBCbB^{1 }}$ \\ Stepben Buetow, $P b D^{1}$ \\ Arch G. Mainous III, PbD ${ }^{2}$ \\ Gregory Young ${ }^{1}$ \\ Gregor Coster, MSc, $M B C b B^{1}$ \\ Bruce Arroll, $\mathrm{PbD}, \mathrm{MBChB^{1 }}$ \\ 'Department of General Practice \\ and Primary Health Care, University of \\ Auckland, New Zealand \\ ${ }^{2}$ Department of Family Medicine, Medical \\ University of South Carolina, Charleston, SC
}

Conflicts of interest: none reported

\section{CORRESPONDING AUTHOR}

Ngaire Kerse, $\mathrm{PhD}, \mathrm{MBChB}$ Department of General Practice and Primary Health Care Faculty of Medical and Health Sciences University of Auckland

Private Bag 92019

Auckland, New Zealand

n.kerse@auckland.ac.nz

\begin{abstract}
PURPOSE We assessed the relationship between 4 attributes of the physicianpatient relationship and medication compliance.

METHODS We conducted a waiting room survey of patients consulting 22 general practitioners in 14 randomly selected practices in Auckland, New Zealand $(81 \%$ response rate). A total of 370 consecutive patients (75\% response rate) completed survey instruments about 4 attributes of the physician-patient relationship. Continuity of care (assessed from use of a usual physician, length of continuity, and perceived importance of continuity) and trust in the physician were ascertained before the consultation. After the consultation the Patient Enablement Index measured the physician's ability to enable patients in self-care, and concordance between the patient and physician was measured by a 6-item inventory of perceived agreement about the presenting problem and management, were ascertained immediately after the consultation. Compliance with prescribed medication therapy was ascertained by telephone follow-up 4 days after the consultation.
\end{abstract}

RESULTS Overall, 220 patients (61\%) received a prescription, and $79 \%$ of these patients were taking the medication at follow-up. In a univariate analysis adjusted for clustering, only trust and physician-patient concordance were significantly related to compliance. In analysis further adjusted for health and demographic factors, physician-patient concordance was independently related to compliance (odds ratio $=1.34,95 \%$ confidence interval, 1.04-1.72).

CONCLUSIONS Primary care consultations with higher levels of patient-reported physician-patient concordance were associated with one-third greater medication compliance. An emphasis on understanding and facilitating agreement between physician and patient may benefit outcomes in primary care.

Ann Fam Med 2004;2:455-461. DOI: 10.1370/afm.139.

\section{INTRODUCTION}

7 he physician-patient relationship is integral to the successful delivery of primary health care. ${ }^{1}$ The quintessential character of the physician-patient relationship, however, has been difficult to define, especially in the face of mounting societal pressures for fiscal constraint and population-based health care. ${ }^{2}$

In any consultation several attributes of the physician-patient relationship may affect the outcome, including a longitudinal relationship between patient and physician (continuity of care) ${ }^{3}$; concordance, or agreement, between the patient and physician on the problem or need and its management ${ }^{4}{ }_{i}$ patients' trust in their physician to act in their best interest ${ }_{i}$ and the ability of the physician to enable the patient toward effective self-care (patient enablement). ${ }^{5}$ Which of these aspects is most closely associated with outcomes of primary health care has not been established.

Continuity of care between patients and physicians has been associ- 
ated with improved health services use and preventive care $_{1}^{3,6}$ the physician's understanding of the psychosocial aspects of patient care, ${ }^{7}$ and satisfaction with care. ${ }^{8}$ As continuity appears to be a general construct under which a variety of concepts fit ${ }^{9}$ several tools have been developed to measure different aspects of continuity. Which particular aspect confers most benefit is unknown.

The level of agreement or concordance between physician and patient about the nature of the patient's problem is associated with resolution of nonspecific signs and symptoms. ${ }^{10}$ Less rigorous methods show an association between concordance and patient adherence to management and medication plans. ${ }^{4,11,12}$ Patients are less likely to return for visits when there is a lack of physician-patient concordance, ${ }^{13}$ although the relationship is inconsistent. ${ }^{14,15}$ Trust is said to be essential to the medical consultation and is related to continuity and patient satisfaction. ${ }^{16,17}$ The ability of the physician to enable the patient toward effective self-care is a marker of consultation quality. ${ }^{5}$

Medication prescribing is a core component of medical care, and patient compliance with recommendations to take medications varies. ${ }^{18}$ In this study, we sought to establish potential associations between attributes of the physician-patient relationship and medication compliance. We report an investigation measuring self-reported continuity and trust before the consultation, and physician-patient concordance and enablement immediately after the consultation, and we then relate these attributes to subsequent medication compliance.

\section{METHODS}

\section{Design}

We asked general practitioners, randomly selected from the Auckland metropolitan area of New Zealand, for permission to approach consecutive patients or those responsible for the patients in their practice waiting room. Patients and caretakers who were bringing a child or adult under their care were approached in the waiting room and then invited to give written informed consent to participate. Respondents completed survey instruments before and immediately after their consultation. They were telephoned 4 days later to establish compliance with medication therapy. We made 4 attempts at telephone contact at differing times of the day for a 2-day period. The Auckland Ethics Committee approved the study.

\section{Survey Instrument}

The survey instrument we used has been used in an international study of continuity and trust ${ }^{16,17}$ and was adapted for a New Zealand audience. The instrument asked about standard demographic and health information, and contained several validated tools and a physician-patient concordance measure.

\section{Measures: Survey Part 1}

Part 1 of the survey was completed before the consultation and included the following components.

\section{Health and Demographic Information}

For ethnicity, we used patients' self-described ethnicity in response to the 1996 New Zealand census question. Education was based on high-school completion, and perceived economic status was measured with the following question: "Thinking of your money situation, would you say that your household (choose one): can't make ends meet; has just enough to get along on; is comfortable." In addition, we used eligibility for the community services (low-income assistance) card, as a marker of socioeconomic status. Health status was estimated from the presence of a chronic illness and from scores on the EuroQol 5-dimensional questionnaire (EuroQol5D) ${ }_{1}^{19}$ a 5 -item health-related quality-of-life measure.

\section{Source of Care}

We ascertained source of care by asking, "Is there one particular surgery that you/the patient usually go to if you are sick or need advice about your health? (For example, a general practice.)" and "If yes, is there a particular doctor you/the patient usually see at this surgery?" This approach has been validated with the Usual Provider Continuity Index ${ }^{20}$ and shows patients' ability to identify with a single source of care.

\section{Continuity of Care}

We assessed continuity of care with 3 measures. Length of continuity was established by asking, "How long have you/the patient been seeing this doctor?" This approach has been validated with other continuity measures. ${ }^{21}$ The importance of continuity was assessed by asking, "How important is it to you to see the same GP every time you have a health problem?" with responses recorded on a Likert scale ranging from 1 (not important at all) to 5 (very important). ${ }^{22}$ Finally, we calculated the Usual Provider Continuity Index ${ }^{23}$ - the proportion of consultations with the usual physicianone of the most widely used measures of continuity. ${ }^{9}$

\section{Trust in the Physician}

We measured trust with the Trust in Physician Scale, ${ }^{24}$ which yields a score ranging from 11 to 55 , with higher scores indicating more trust. Because we measured trust before the consultation, and this measure was intended to assess established trust (and the capacity to develop 
it), only patients who reported having a usual general practitioner answered this section.

\section{Measures: Survey Part 2}

Part 2 of the survey was completed immediately after the consultation and included the following components.

\section{Physician-Patient Concordance}

We assessed agreement between physician and patient with the following questions:

1. "To what extent do you think the doctor understands why you came in today?"

2. "How well do you think the doctor understood you today?"

3. "To what extent did you and the doctor agree about the main problem or need today?"

4. "To what extent did you and the doctor agree about what to do about the problem or need?"

5. "To what extent do you and the doctor agree on what part you play in making decisions about health?"

6. "To what extent do you and the doctor agree on who is responsible for different aspects of care?"

The response to each question was recorded on a Likert scale ranging from 1 (completely) to 4 (not at all). We dichotomized the results to 1 (completely) and 0 (all other responses). Results for the 6 questions were then summed to give a cumulative score between 0 and 6 , with higher scores indicating greater concordance. We calculated the Cronbach $\alpha$ for internal consistence of the scale and report the distribution of scores.

\section{Patient Enablement}

We used the Enablement Index ${ }^{5}$ to assess whether the physician enabled the patient toward effective self-care. This index, validated in primary care against patient satisfaction, asks whether patients are more or less able to cope with life, understand and cope with their illness, and help themselves as a result of the consultation with the physician. The responses are scored from 1 to 4 , with higher scores meaning more enablement.

\section{Measures: Medication Compliance}

To assess medication compliance, we first asked the patients whether they received a prescription on the day of the consultation. Four days later, we telephoned patients and asked whether they had filled the prescription, were taking the medication, and if not, why not. Patients were classified as compliant if they had received a prescription and were taking the medication at the 4day follow-up or if they were not taking it at follow-up because it had been a repeated prescription and they already had enough medication. If they were not taking
Figure 1. Flow of primary care patients in a study about medication compliance.

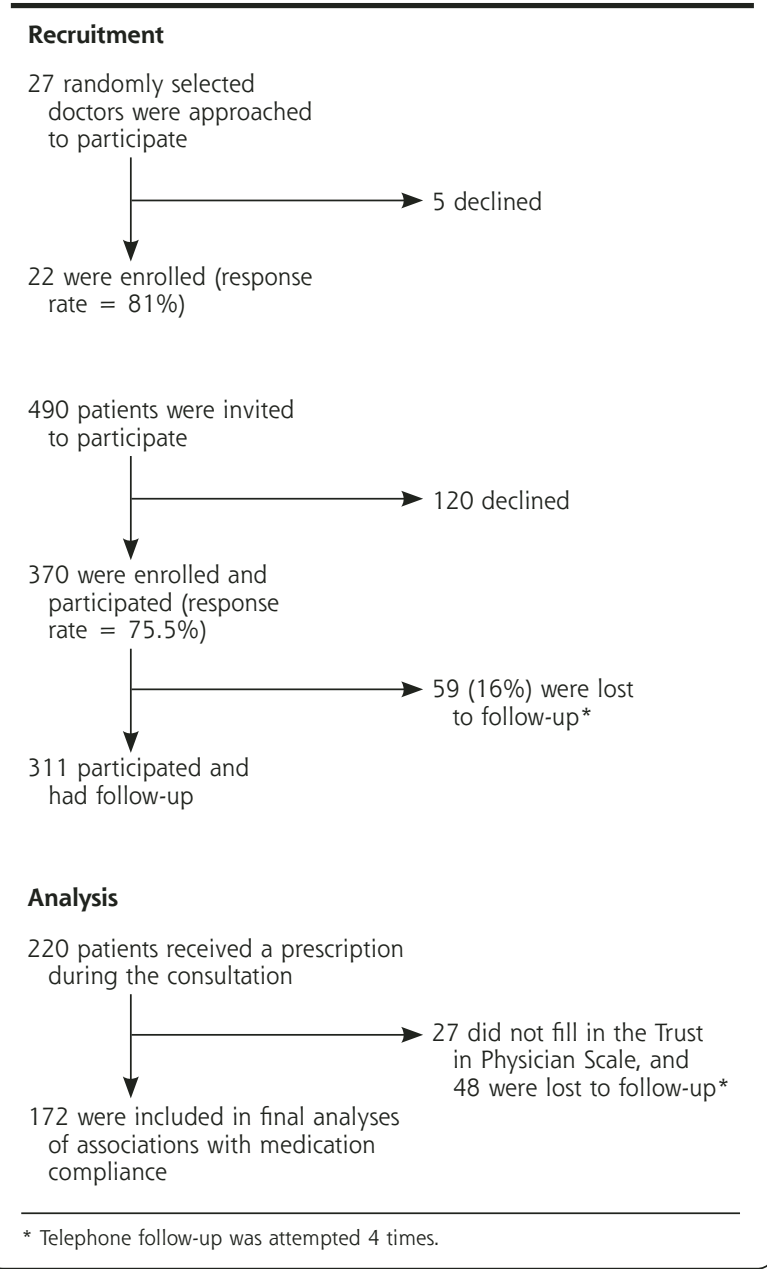

the prescribed medication at follow-up for any other reason, they were classified as noncompliant. Those who had not received a prescription during the consultation were not included in the compliance analysis.

\section{Analyses}

We produced statistics describing the sample and summary responses to the survey with SPSS v11 (SPSS Inc, Chicago, Ill). Intraclass correlations were computed for compliance within practices from a 1-way analysis of variance using Stata 7.0 (Stata Corp, College Station, Tex).

To examine relationships between consultation characteristics and the dichotomous outcome of compliance, we performed logistic regression analysis. As observations on patients were not independent within groups (practices) but were independent across groups, we adjusted for clustering with Stata 7.0. Multivariable analyses included health status, age, ethnicity, and education as control variables, and the results are reported as odds ratios. We also assessed for interaction effects 


\begin{tabular}{|lc}
\hline \multicolumn{2}{l}{ Table 1. Demographic Characteristics of a Sample } \\
of Primary Care Patients Gathered \\
in Waiting Rooms (N = 370) \\
\hline Characteristic & Mean (SD) \\
\hline Age of patients, years & $41.3(15.8)$ \\
No. of consultations in last year & $5.3(6.7)$ \\
EuroQol-5D score & $8.0(2.5)$ \\
& No. (\%) \\
\cline { 2 - 2 } Sex, female & $247(68.1)$ \\
Ethnicity & \\
White & $276(74.5)$ \\
Maori & $46(12.4)$ \\
Pacific Islander & $32(8.6)$ \\
Other & $16(4.3)$ \\
Economic status & $122(34.2)$ \\
Community services card & $26(7.0)$ \\
Can't make ends meet & $144(38.9)$ \\
Have just enough & $189(51.1)$ \\
Am comfortable & \\
Education & $77(22.8)$ \\
Less than high school & $144(42.7)$ \\
Completed high school & $116(34.4)$ \\
Some higher qualification & \\
Person consulting & $276(76.2)$ \\
Myself & $81(22.4)$ \\
A child I am caring for & $5(1.4)$ \\
An adult I am caring for & $113(30.9)$ \\
\hline Note: Because of rounding, percentages may not all total 100. \\
EuroQol-5D = the EuroQol 5-dimensional questionnaire. \\
\hline
\end{tabular}

on medication compliance. Values were coded as missing if follow-up with the respondent had not been possible. We omitted from the logistic regression model cases that were missing values for any of the variables.

\section{RESULTS}

Twenty-two physicians of 27 approached in 14 surgeries were enrolled in the study. Of 490 consecutive patients, 370 were enrolled $(75.5 \%)$. The number of patients attending on the recruitment days ranged from 5 to 40 . On average, 16 patients were enrolled from each physician (range, 2-34 patients per physician; SD, 9.5). Figure 1 shows the disposition of patients and the number included in the multivariable analysis. The 59 patients who could not be followed up by telephone were indistinguishable from those that were by age ( 41.4 vs 42.1 years, $P=.79$ ), sex $(62 \%$ vs $70 \%$ female, $P=.25)$, and presence of a chronic disease $(33 \%$ vs $38 \%, P=.52)$.

Table 1 shows the demographic and health status of the sample. Three quarters of the patient sample
Table 2. Consultation Characteristics of a Sample of Primary Care Patients Gathered in Waiting Rooms ( $N=370)$

\begin{tabular}{|c|c|}
\hline Characteristic & Value \\
\hline \multicolumn{2}{|l|}{ Trust } \\
\hline Trust in Physician Scale score, mean (SD) & $44.57(6.25)$ \\
\hline \multicolumn{2}{|l|}{ Source of care } \\
\hline Has a usual source of care (clinic), No. (\%) of patients & $326(88.1)$ \\
\hline Has a usual doctor, No. (\%) of patients & $279(75.4)$ \\
\hline \multicolumn{2}{|l|}{ Continuity of care } \\
\hline UPC Index score, mean (SD) & $0.75(0.31)$ \\
\hline \multicolumn{2}{|l|}{ Length of care with same doctor, No. (\%) of patients } \\
\hline$<1$ year & $82(24)$ \\
\hline $1-2$ years & $56(16)$ \\
\hline $3-5$ years & $69(20)$ \\
\hline $6-10$ years & $49(14)$ \\
\hline$>10$ years & $91(26)$ \\
\hline \multirow{2}{*}{\multicolumn{2}{|c|}{$\begin{array}{l}\text { Importance of seeing same doctor at each visit, } \\
\text { No. (\%) of patients }\end{array}$}} \\
\hline & \\
\hline Very important & $152(41.3)$ \\
\hline Quite important & $150(40.9)$ \\
\hline Neutral & $40(10.9)$ \\
\hline Not very, not important at all & $26(8.2)$ \\
\hline \multicolumn{2}{|l|}{ Enablement } \\
\hline Enablement Index score, mean (SD) & $2.1(0.75)$ \\
\hline \multicolumn{2}{|l|}{ Doctor-patient concordance } \\
\hline \multicolumn{2}{|l|}{ No. (\%) of patients responding "completely"* } \\
\hline $\begin{array}{l}\text { To what extent do you think the doctor understands } \\
\text { why you came in today? }\end{array}$ & $294(89.1)$ \\
\hline $\begin{array}{l}\text { How well do you think the doctor understood you } \\
\text { today? }\end{array}$ & $293(88.5)$ \\
\hline $\begin{array}{l}\text { To what extent did you and the doctor agree about } \\
\text { the main problem or need today? }\end{array}$ & $280(84.5)$ \\
\hline $\begin{array}{l}\text { To what extent did you and the doctor agree about } \\
\text { what to do about the problem or need? }\end{array}$ & $278(84.2)$ \\
\hline $\begin{array}{l}\text { To what extent do you and the doctor agree on what } \\
\text { part you play in making decisions about health? }\end{array}$ & $241(73.9)$ \\
\hline $\begin{array}{l}\text { To what extent do you and the doctor agree on who } \\
\text { is responsible for different aspects of care? }\end{array}$ & $239(74.7)$ \\
\hline Overall score, mean (SD) & $3.6(1.9)$ \\
\hline \multicolumn{2}{|l|}{ Compliance } \\
\hline \multicolumn{2}{|l|}{ No. (\%) of patients responding "yes" } \\
\hline Received prescription during consultation & $220(61.3)$ \\
\hline Picked up prescription from pharmacy ${ }^{\dagger}$ & $150(86.7)$ \\
\hline Taking medication ${ }^{\dagger}$ & $136(78.6)^{\ddagger}$ \\
\hline $\begin{array}{l}\text { Note: Because of rounding, percentages may not all total } 100 \text {. } \\
\text { UPC = Usual Provider Continuity. } \\
\text { * Responses were missing for } 35 \text { patients. } \\
\text { † Values are based on } 172 \text { patients who received a prescription an } \\
\text { † An additional } 8 \text { patients received a repeated prescription and al } \\
\text { enough medication. }\end{array}$ & $\begin{array}{l}\text { had follow-up. } \\
\text { ready had }\end{array}$ \\
\hline
\end{tabular}

consulted the physician for themselves. The remainder were bringing a child or adult under their care. About one third of respondents (30.9\%) had a major illness, and the average number of consultations in the previous year was 5.3 (SD, 6.7 consultations). 
physician is the key coordinator of prescribing, and correlates of this outcome will be useful in designing interventions to improve compliance.

Patterns in the source of care, usual provider continuity, and reported importance of continuity are comparable between our sample and a sample of US primary care patients. ${ }^{16}$ Medicaid populations have been found to have lower levels of continuity of care, but continuity was associated with fewer hospitalizations. ${ }^{6}$ Our finding that various continuity measures were not associated with compliance is surprising and contrary to the findings of previous research. ${ }^{25} \mathrm{We}$ concur with Christakis ${ }^{28}$ that continuity may operate differently in different populations and that relatively high levels of continuity and quality of care might combine to create a ceiling effect, concealing the impact of continuity evident in other subpopulations.

As with continuity of care, levels of trust in one's physician are similar among patients in the United States, the United Kingdom, ${ }^{16}$ and New Zealand. In this study, trust was not independently associated with medication compliance, nor was enablement, which questions their utility as markers of quality in primary care. ${ }^{5}$

\section{Implications for Practice, Policy, and Future Research}

This study is the first to add medication compliance to the outcomes positively related to physician-patient concordance, ${ }^{10,12}$ and our findings suggest that efforts to facilitate physician-patient concordance may improve primary care outcomes. Ensuring that the patient understands the physician, that there is agreement about the nature of the patient's problem, and that management is acceptable will require excellent communication skills, especially listening skills. These skills could be a focus for educators, planners, and evaluators.

In conclusion, this study points to the importance of concordance in the physician-patient relationship during the delivery of primary health care and extends previous work by exploring various dimensions of the relationship simultaneously. Whether the physician-patient concordance is improved by using the patient-centered method ${ }^{29}$ may be a fruitful avenue for research.

To read or post commentaries in response to this article, see it online at http://www.annfammed.org/cgi/content/full/2/5/455.

Key words: Physician-patient relations; primary health care; office visits; patient compliance; prescriptions, drug; drug therapy

Submitted October 18, 2003; submitted, revised, February 10, 2004; accepted February 17, 2004.
A version of this article was presented at the Academy Health Scientific Meeting, 2003, Nashville, Tenn.

Funding support: Support for this study was provided by the Health Research Council of New Zealand in the form of a University of Auckland Summer Studentship grant. In addition, the Department of General Practice and Primary Health Care provided project costs, and the manuscript was prepared while Dr. Kerse was supported by a Harkness Fellowship from the Commonwealth Fund.

Acknowledgments: We thank the general practitioners, staff, and patients for their willing participation. Roger Rosenblatt kindly made comments on a previous draft of the manuscript.

\section{References}

1. Strasser R. The doctor-patient relationship in general practice. Med J Aust. 1992;156:334-338.

2. Balint J, Shelton W. Regaining the initiative. Forging a new model of the patient-physician relationship. JAMA. 1996;275:887-891.

3. Christakis DA, Mell L, Wright JA, Davis R, Connell FA. The association between greater continuity of care and timely measles-mumpsrubella vaccination. Am J Public Health. 2000;90:962-965.

4. Vedsted P, Mainz J, Lauritzen T, Olesen F. Patient and GP agreement on aspects of general practice care. Fam Pract. 2002;19:339-343.

5. Howie JG, Heaney DJ, Maxwell M, Walker JJ. Quality at general practice consultations: cross sectional survey. BMJ. 1999;319:738-743.

6. Gill J, Mainous Al. The role of provider continuity in preventing hospitalizations. Arch Fam Med. 1998;7:352-357.

7. Gulbrandsen P, Hjortdahl P, Fugeli P. General practitioners' knowledge of their patients' psychosocial problem: multipractice questionnaire survey. BMJ. 1997;314:1014-1018.

8. Hjortdahl P, Laerum E. Continuity of care in general practice: effect on patient satisfaction. BMJ. 1992;304:1287-1290.

9. Saultz JW. Defining and measuring interpersonal continuity of care. Ann Fam Med. 2003;1:134-143.

10. Bass MJ, Buck C, Turner L, Dickie G, Pratt G, Robinson C. The physician's actions and the outcome of illness in family practice. J Fam Pract. 1986;32:34-47

11. Stanton AL. Determinants of adherence to medical regimes by hypertensive patients. J Behav Med. 1987;10:377-394.

12. Maly RC, Leake B, Frank JC, DiMatteo MR, Reuben DB. Implementation of consultative geriatric recommendations: the role of patient-primary care physician concordance. J Am Geriatr Soc. 2002;50:1372-1380.

13. Buetow S, Adair V, Coster G, Hight M, Gribben B, Mitchell E. GP care for moderate to severe asthma in children: what do infrequently attending mothers disagree with and why? Fam Pract. 2003;20:155-161.

14. Scheitel SM, Boland BJ, Wollan PC, Silverstein MD. Patient-physician agreement about medical diagnoses and cardiovascular risk factors in the ambulatory general medical examination. Mayo Clin Proc. 1996;71:1131-1137.

15. Britt H, Harris M, Driver B, Bridges-Webb C, O'Toole B, Neary S. Reasons for encounter and diagnosed health problems: convergence between doctors and patients. Fam Pract. 1992;9:191-194.

16. Mainous AG III, Baker R, Love M, Gray DP, Gill J. Continuity of care and trust in one's physician: evidence from primary care in the United States and the United Kingdom. Fam Med. 2001;33:22-27.

17. Baker R, Mainous AG III, Gray DP, Love MM. Exploration of the relationship between continuity, trust in regular doctors and patient satisfaction with consultations with family doctors. Scand J Prim Health Care. 2003;21:27-32. 
18. Cartwright A. Medicine taking by people aged 65 or more. $\mathrm{Br}$ Med Bull. 1990;46:63-76.

19. The EuroQol Group. EuroQol: a new facility for the measurement of health-related quality of life. Health Policy. 1990;16:199-208.

20. Reid RJ, Barer ML, McKendry R, et al. Patient-Focused Care Over Time: Issues Related to Measurement, Prevalence and Strategies for Improvement Among Patient Populations. Ottawa, Canada: Canadian Health Services Research Foundation. Final report, project \#RC20276-10, 2003.

21. Reid R, Haggerty J, McKendry R. Defusing the Confusion: Concepts and Measures of Continuity of Health Care. Ottawa, Canada: Canadian Health Services Research Foundation; 2002.

22. Nutting PA, Goodwin MA, Flocke SA, Zyzanski SJ, Stange KC. Continuity of primary care: to whom does it matter and when? Ann Fam Med. 2003;1:149-155.

23. Starfield B. Primary Care: Concept, Evaluation, and Policy. New York, NY: Oxford University Press; 1992.
24. Anderson L, Dedrick R. Development of the trust in physician scale: a measure to assess interpersonal trust in patient-physician relationships. Psychol Rep. 1990;67:1091-1100.

25. Charney E, Bynum R, Eldredge D, et al. How well do patients take oral penicillin? A collaborative study in private practice. Pediatrics. 1967;40:188-195.

26. Kwoh CK, O'Conner GT, Regan-Smith MG, et al. Concordance between clinicians and patient assessment of physical and mental health status. J Rheumatol. 1992;19:1031-1037.

27. Cramer JA. Consequences of intermittent treatment for hypertension: the case for medication compliance and persistence Am J Manag Care. 1998;4:1563-1568

28. Christakis D. Continuity of care: process or outcome? Ann Fam Med. 2003;1:131-133.

29. Stewart M, Roter D. Communicating with Medical Patients. Newbury Park, Calif: Sage Publications; 1989. 